\title{
Implementation of Competences of Social and Environmental Responsibility in IT Engineering Degrees
}

\author{
Minano, Rafael
}

Fernandez Aller, Celia

Anguera, Aurea

\begin{abstract}
In the present globalized world, the impacts of engineering are growing in importance, society is becoming more aware of them, and more and more universities are including ethical and social issues into their engineering degree programs. This article describes the experience of developing competences of ethical, social and environmental responsibility in undergraduate IT engineering degrees at the Technical University of Madrid. The implementation of these competences has evolved in recent years and currently they are developed in two specific subjects in the first and third year, and that work is completed in the Final Year Project. This model allows us to reach all the students at different times along their studies and with a acceptable level of depth. It is an integral experience, where appropriate contents, teaching methodologies and assessment methods have been adapted to deal with social issues in our academic context. As lessons learned, we highlight the effectiveness this model for developing the aforementioned competences and the important role of external references (from professional, governmental and academic institutions) to integrate ethical, social and environmental aspects into engineering degrees.
\end{abstract}

\section{Categories and Subject Descriptors}

- Social and professional topics $\rightarrow$ Professional topics $\rightarrow$ Computing education;500

- Social and professional topics Professional topics $\rightarrow$ Computing industry $\rightarrow$ Sustainability;300

- Social and professional topics Professional topics $\rightarrow$ Computing profession $\rightarrow$ Codes of ethics;300

- Social and professional topics $\rightarrow$ Computing / technology policy;300

\section{Keywords}

Engineering education; educational experiences; generic competences; social issues; sustainability; engineering ethics.

\section{INTRODUCTION}

It is increasingly common that social, environmental and ethical issues are included in academic engineering degree programs. In the present globalized world, the impacts of the engineering profession are growing in importance, society is becoming more aware of them, and both professionals and institutions have to assume the responsibility that their expertise and the impacts of their actions confer to them.

A reference about how to introduce these topics into the academic programs is given by several accrediting agencies such as ABET and EUR-ACE, or innovative initiatives as CDIO (Conceiving, Designing, Implementing \& Operating). They include competences and learning outcomes directly related to social, environmental and ethical responsibility of engineering, and they support their integration into academic programs.

ABET includes in their professional competences "the understanding of professional and ethical responsibility", and "the broad education necessary to understand the impact of engineering solutions in a global and societal context" [1].

The European Accreditation Agency EUR-ACE considered that graduates should be able, , as a transferable skill, to "demonstrate awareness of the health, safety and legal issues and responsibilities of engineering practice, the impact of engineering solutions in a societal and environmental context, and commit to professional ethics, responsibilities and norms of engineering practice" [15]. Besides this awareness, its most recent framework standards includes as programme outcomes the "ability to consult and apply codes of practice and safety regulations in their field of study", the "ability to inform judgements that include reflection on relevant social and ethical issues" and the "ability to manage complex technical or professional activities or projects in their field of study, taking responsibility for decision making" [16].

Last, the CDIO Syllabus [9] incorporates professional ethics and social responsibility as personal competences, and highlights the importance of knowing the societal and environmental context in order to guide any project and technological innovation to a sustainable development. 
In the context of the European Union, the framework for qualifications of the European Higher Education Area (EHEA) includes into the so-called 'Dublin Descriptors" some relevant learning outcomes for education for ethical and social responsibility, and it is widely considered as a opportunity to introduce new educational elements for preparing students on those topics [26][35]. From the field of sustainability, the Barcelona Declaration and the decade of UNESCO for training in sustainability, also clearly reflect the relevance of developing such competences [17][27][29]

But there are some indications that the overall impact of these external demands has been limited -to say the least- and there is no evidence that the way in which universities currently prepare students in science and engineering for social responsibility is adequate or sufficient. There is some agreement about knowledge, skills and teaching methodologies to develop these competences but "some important and persistent barriers stand in the way of its sustained development. What is needed are both bottom-up teaching initiatives from individuals or groups of academic teachers, and top-down support to secure appropriate embedding in the university" [35].

With this paper, we aim to share the experience of developing competences of professional ethics, and social and environmental responsibility for students of the Software and Computer Engineering degrees of the Technical University of Madrid (UPM). We consider it an example of both bottom-up and topdown approach, as it is proposed in Zandvoort [35]. It is a work in progress and results are only partially available. Section 2 provides an outline of both the Spanish and the UPM context for developing these competences, and explains our incipient experience in one subject of IT engineering degrees. In section 3 , we present in detail the implementation of the competence "social and environmental responsibility" along the new degrees that started in 2014, where the developing of this competence is assigned to two compulsory subjects, as well as to the Final Year Project (hereafter FYP). Finally, a reflection about this experience is presented, giving some proposals for future actions.

\section{CONTEXT AND BACKGROUND}

The Spanish universities are integrated in the European Higher Education Area (EHEA), so they have included in every Bachelor and Masters degrees the Dublin Descriptors, so bachelor's students should "have the ability to gather and interpret relevant data (usually within their field of study) to inform judgments that include reflection on relevant social, scientific and ethical issues". In addition, each university determines a set of generic competences that must be included in every degree. Some universities have defined competences directly or indirectly related to professional ethics, social responsibility or sustainability. Some instances are: "responsible and ethical commitment"1, "act with responsibility and professional ethics" ${ }^{2}$ or "sustainability and social commitment" 3

The Technical University of Madrid (UPM) has included as a generic competence the "respect to the environment" (hereafter $\mathrm{RtE}$ ) in all its degrees. Besides, the UPM Educational Model

\footnotetext{
${ }^{1}$ Universidad de Valladolid: www.uva.es

${ }^{2}$ Universidad de Extremadura: www.unex.es

${ }^{3}$ Universidad Politécnica de Cataluña: www.upc.edu
}

notes that "the training of engineers and architects must not only take account of scientific and technical knowledge, but also be in harmony with ethical values" and proposes -as a competence that must be developed- the "understanding of the profession and the social commitment to society and the environment, with the duty to respect their ethical code" [31].

As a result of an educational innovation project where the faculty from different schools of the UPM were involved, a web site with teacher support resources about generic competences was developed [32]. Some guidelines for the competence RtE are given. Although it is oriented to environmental impacts, some references to ethical issues and social responsibility issues are included. Most of the methodological proposals which are made focusing on sustainability can be easily adapted to work ethical and social issues.

In spite of the fact that there is not a global plan for the implementation of the generic competence RtE at the UPM degrees, there are some interesting experiences driven by both UPM Schools and some research groups. Some relevant examples are the teaching strategies of the School of Agricultural Engineering -oriented towards environmental sustainability-, the global strategies of the School of Industrial Engineering about Corporate Social Responsibility and sustainability, or the experiences of service learning at the School of Mining and Energy Engineering. Some research groups combine teaching and research practice in different areas such as sustainability, public health, social inclusion and international cooperation for development.

In relation to specific degrees, the Spanish Council of Universities makes recommendations for each official degree about the competences that students should achieve during their studies. Each university and college incorporates these recommendations differently in compulsory subjects, elective specific subjects, transversal inclusion into compulsory subjects or into the FYP. As an example, the recommendations for the degrees related to IT engineering include competences such as "the capacity to understand and apply the ethical responsibility, legislation and professional deontology of computing engineering" and the "ability to analyze and assess the social and environmental impact of technical solutions" [5].

The degrees of Software and Computer Engineering of the UPM, taught at the School of Computer Systems Engineering (ETSISI) -where we have developed the experience described in this paper-, are an example of the potential impact of the involvement of professional organizations in the development of curricula. The programs of these eight-semester degrees, developed in 2009 according to the EHEA, are based largely on the recommendations of the Association for Computing Machinery (ACM) [2]. Some of them are the inclusion of ethical and social issues at the core of the curriculum, making very concrete proposals on compulsory and optional modules, and the introduction of compulsory topics in other subjects.

Following these recommendations, "Social, Legal, Ethical and Professional Issues" (SLEPI) is a compulsory subject $\left(6\right.$ ECTS $^{4}$ ) in the first year of the Software and Computer Engineering degrees of the UPM. While attending to this course, the students

\footnotetext{
${ }^{4}$ European Credit Transfer System, that represents 25-30 hours of student's work (lessons, laboratories, team work, homework, individual study, assessment, etc.)
} 
have to develop the generic competence RtE and "critical thinking" -compulsory in the UPM- and the competences recommended by the Spanish Council of Universities for IT degrees explained in the introduction.

We must say that apart from SLEPI, the students rarely work on any aspect of the competence $\mathrm{RtE}$ along the rest of the degree. In the FYP, the tutor's assessment report includes some questions on whether the students have considered the social impact of the developed application and also whether that application contributes positively to the environment, including an analysis of the environmental impact of the product. But no further actions to support the achievement of these results were taken.

\subsection{The experience of the subject "Social, Legal, Ethical and Professional Issues"}

The course syllabus includes different topics related to the professional performance of IT engineering and its relationship with society, being the legal issues -such as intellectual property and data protection- the core of the subject. Since 2009, ethical and social issues have increased their presence in the contents, representing nowadays the equivalent of 1 ECTS and a $25 \%$ of the final grade. The students get familiarized with engineering professional values, professional codes of ethics, both social and environmental impacts of IT, the digital divide and the basic principles of Corporate Social Responsibility.

Throughout the course, active methodologies are used, fostering students participation with frequent debates in the classroom, case discussions, dilemmas, monographs, expert lectures or visits to research centers where their work has a significant social impact, such as the Digital Accessible Home or the CITSEM (Software Technology Center and Multimedia Systems for Sustainability).

Despite SLEPI in not a technical subject, the official questionnaires about the level of students' satisfaction with the teaching -in the last three years- show that the average for SLEPI is higher than the global average for all the subjects in the programme.

As degrees of Computer and Software Engineering were going to be updated in 2014 increasing the contents related to social and ethical issues, during the course 2013-14 we started to develop some evaluation tools and rubrics adapted to these contents. The assessment of ethical and social responsibility competences is a challenge [10] [18] [35] and, to start with, we decide to conduct an experiment for measuring the progress in ethical reasoning skills in the professional field, adapting the Pittsburgh-Mines Engineering Ethics Assessment Rubric [28]. We checked the effectiveness of our teaching methodology with professionalethical dilemmas, contrasting the students' progress in three dimensions: ethical sensitivity, ethical analysis and decision making. Figure 1 shows such progress with the descriptive data of a variable, SUM ALL, that integrates the results in the three cited categories $^{5}$.

These positive results encouraged us to adapt that model to some subjects of the new programs and to develop a proposal for including social and ethical issues in the Final Year Project. Next section presents how the competence called "social and environmental responsibility" is being implemented in the new degrees.

${ }^{5}$ This experiment is explained in detail in a paper that has been submitted to Science and Engineering Ethics.

\section{THE COMPETENCE "SOCIAL AND ENVIRONMENTAL RESPONSIBILTY” IN THE NEW DEGREES.}

In 2014 the UPM started a new degree in Information Systems and the degrees of Computer and Software Engineering were updated. The three degrees are developed in eight semesters and have a common core in the two first years. All of them include as a generic competence the "social and environmental responsibility" (hereafter SER). This competence extends the former "respect to the environment" (RtE) including a deeper approach to the ethical and social aspects of IT engineering. Specifically, it has been defined as the "knowledge, skills and attitudes needed to integrate into the profession, the social, environmental and ethical issues that affect IT engineering in a responsible and balanced way" [25].

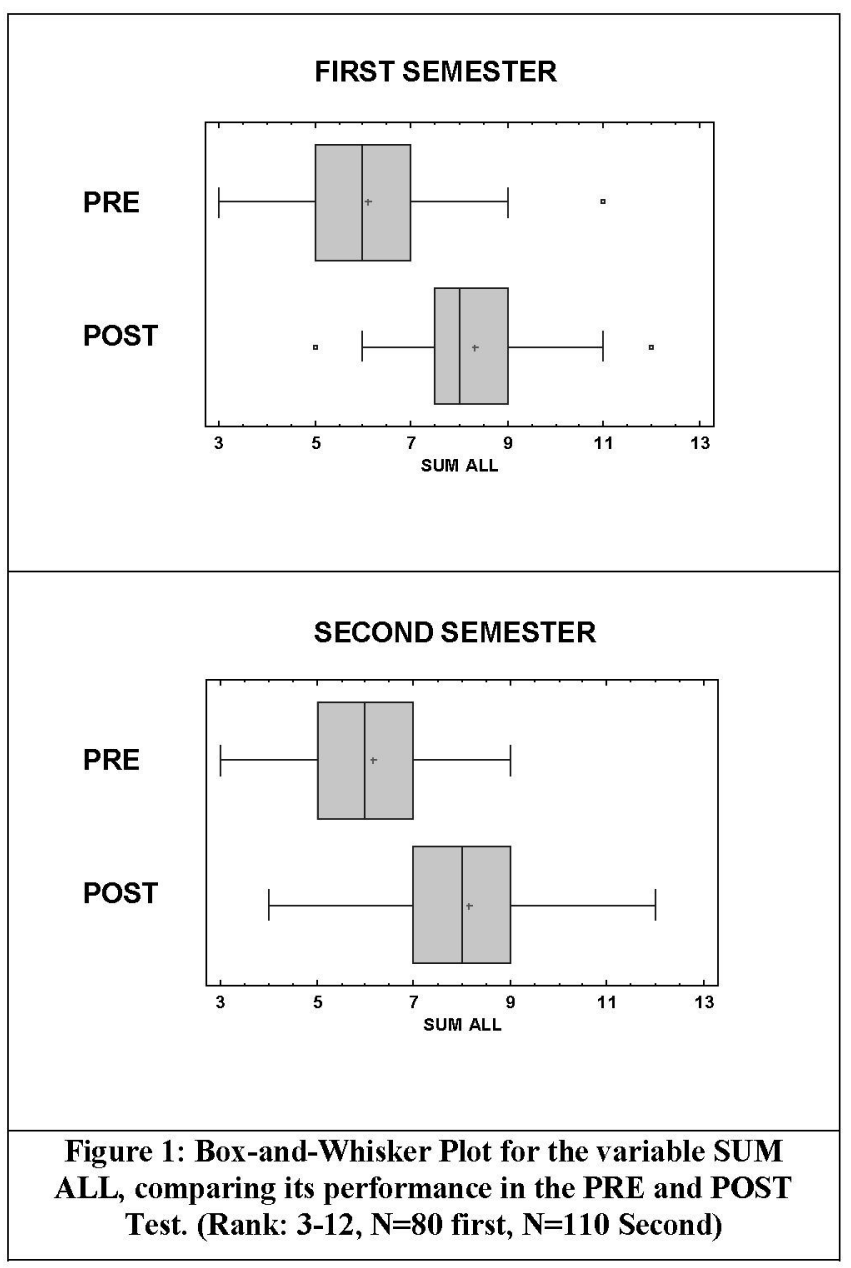

The competence SER will be developed at two levels: knowledge of problematic issues, ethical principles and main regulations; and skills for analyzing and integrating the professional responsibility criteria in specific engineering solutions. The competence has been assigned to two compulsory subjects of 3 ECTS: "Ethical and Social Issues" in the 2nd semester and "Legal and Professional Issues" in the 5th semester, and it is also included in the competences to be developed and assessed in the Final Year Project (FYP). 
The following subsections explain more extensively how the SER competence is being developed at each stage.

\subsection{The subject "Ethical and Social Issues"}

This subject is included in the 2nd semester of the three IT engineering degrees of the ETSISI. Last year it had 318 registered students. The development of two generic competences: SER and "critical thinking" has been assigned to this subject in the teaching plan of this School.

As its name suggests, it deals with a wide variety of topics. We had as a main reference the ACM's Curriculum Guidelines, specifically the body of knowledge related to Social Issues and Professional Practice [4]. The syllabus has four main chapters: social context, professional ethics, corporate social responsibility (CSR) and current challenges and issues.

In the first chapter, we present a brief introduction to the main concepts of Science, Technology and Society, in order to the students to be aware of the role that technology plays in today's world and understand the interrelationships between society and technology development. Then, we focus on the main impacts of the IT on our society, promoting a reflection about how the IT contribute, or not, to a better society for all. To deepen into the contemporary challenges, at the end of the year, the students have to make a presentation of a monographic work about some of the most relevant issues related to the IT (chapter four in the syllabus). Last year the topics chosen were the digital divide, net neutrality, e-accessibility, privacy, intellectual property, security, cybercrimes and sustainability. In some of them, such as privacy, data protection and intellectual property, the Spanish regulation is introduced and explained.

Our goal is not only to focus on the negative impacts or problems, but also to highlight the potential of ICT to promote social welfare and sustainable human development. We encourage students to look for successful experiences in the fields of ehealth, e-education, e-participation, e-inclusion, or experiences for bridging the digital divide.

In the chapter related to professional ethics, we analyze what the profession offers to society and the main ethical issues that arise in the professional practice of computing engineering (ownership of information, conflicts of interests or values, reporting, security, dual use, etc.) and the principles of professional ethics [3] Besides, we present some deontological codes -ACM [4] and IEEE [20]- and the students get familiarized with them working with professional ethics dilemmas; they can use them to analyze the situation and to argue about the decision that a good professional should make.

We have introduced a chapter related to Corporate Social Responsibility (hereafter CSR) that is not included in the recommendations of the ACM's Curriculum Guidelines. CSR is a result of the power and impact of corporations in today's globalized society in many different areas (labor, social, economic, environmental, technological or political) and entails the need to assume the consequences. By introducing these topics, we want to go beyond the individualistic approach (work place ethics or "micro-ethics") and give due attention to the meso (company, CSR) and macro-level (laws, political system), including topics such as social justice, equity, empowerment of people and environmental sustainability. From our teaching experience, we agree with other authors -[11] [14]- that including CSR in the syllabus is a good and necessary strategy.
In relation to the teaching methodologies, there is a general agreement on the effectiveness of the use of active learning practices linked to appropriate theoretical and empirical input [6] [10] [13] [26] [35]. Our course takes two hours of class per week. The teacher theoretical explanations are often combined with group discussions and debates. In many classes the students get online to search for information in order to solve ethical and professional dilemmas, to analyze controversial cases and make reports about the CSR strategies of ICT companies. It is a propitious subject to present situations where legal issues collide with ethical principles, both professionally and personally. We aim to make the students think critically.

We also encourage the participation of expert professors from other departments and external guest lecturers: teachers involved in cooperation for development projects, UPM researchers on IT technologies for the disabled, CSR managers in IT companies, etc.

The assessment is made taking into account different activities: analysis of practical cases (professional situations which involve social, legal and ethical dilemmas), online activities (discussion forums, debating on texts, test questionnaires) and monographs with oral presentations. In addition, the students have to pass two written tests with objective questions.

The experience of this first year is quite positive, the course has had a good level of acceptance by the students, who value positively the inclusion of these topics in a technological degree.

\subsection{The subject "Legal and Professional Issues"}

This course includes the core of the subject of the previous degree program, focused on the legal aspects of IT engineering. The issues are mainly related to data protection, intellectual property rights, patents and trademarks, electronic commerce, digital signature, cybersecurity and crime. Besides some professional issues such as the regulations of the professional activity and professional associations are explained.

It is a subject of 3 ECTS scheduled in the 5th semester of the program. This allows to deepen into some concepts that arose in the previous subject (Social and Ethical Issues), and to work on more specific issues with the use of laws and regulations, closer to the reality that the students will find as professionals. We have no available results yet, since the new program just started in 2014 , but we expect that being third year students, their greater maturity will allow them to go deeper than in the former programs, where these topics were seen in the first year.

The teaching and assessment methodologies will be similar to that of the subject of Ethical and Social Issues, strengthening the analysis of cases with controversial situations and decisionmaking, in line with current regulations and consistent with the professional ethical principles.

\subsection{The Final Year Project}

In the academic year 2014-15 we have begun to support the development of the SER competence in the FYP. We agree with other authors, [7] [23] [24], in the view that the FYP provides a great opportunity for practicing and evaluating professional skills such as sustainability or social responsibility. It is the closest academic activity to the future engineering projects on which the students will work. Therefore, we are offering to the students and tutors a methodology for working these competences and tutorial support. The goal is to provide them with the knowledge and 
operational techniques that will help them improve the reflection on ethical, social and environmental aspects related to their FYP and their integration, when appropriate, in their work.

Our proposal is based on different resources: the Value-Sensitive Design approach (methodology developed in human-computer interaction research) [12], some proposals from the Social Life Cycle Assessment [30] and methodologies for ethical impact assessment of information technology [8][34].

We distinguish four phases: identification of possible impacts, analysis and selection of the relevant issues, the technical or empirical phase and a final reflection.

In the first phase, all the possible ethical, social and environmental issues or impacts related to the project should be identified. As a previous step, we propose to define the scenario where the work will be developed. The students must consider: i) The technological sector the project is framed in (artificial intelligence, management software, mobile applications, security, intelligent systems...); depending on the sector there are specific ethical, social or environmental issues particularly relevant. ii) Organizational aspects; if the project is part of a broader program, the role it plays in that program must be defined (basic research, development of a module or a specific product, application of a developed product, etc.). iii) The whole life cycle of both the FYP and the broader program. iv) The socio-economic, geographical and cultural context in which the different phases of the project life cycle are developed or may be developed in the future. v) The stakeholders who will be directly or indirectly affected by the implementation of the project in any of its phases, both positive and negatively.

Given this scenario, all possible impacts and ethical, social and environmental issues that may be related to the project will be identified. The goal is not to make an exhaustive list but make sure that major impacts will not go unnoticed.

We propose two methodologies. One is based on a checklist, given a list of categories of both environmental and social impacts, and a list of ethical principles and associated problems, the students will check which of them are related to their project. The list has been compiled taking into account various references from ethical assessment of technology [8], social responsibility management [19] [22] [33] and environmental management [21].

The other approach involves reflecting about a series of questions related to both the main principles of professional ethics and the most common problems in engineering projects. We have adapted the questionnaire designed by Wright [34]

In the second phase of the four previously mentioned, students have to select the most relevant issues to their project from the ones identified in the previous phase, and analyze them in depth. They are asked to accomplish the following tasks: making a detailed description of the impacts selected; identifying stakeholders and how they are affected; identifying regulations, laws, ethical codes related to them; and pondering on the possibilities of an assessment or quantitative evaluation of them.

The third phase is called technical or empirical. The impacts selected in the previous phase will be quantified and measured, using appropriate methodologies depending on the nature of the project. The results will be taken into account when analyzing different alternatives for the project development.
When possible, the students will test the product, to study the interactions with potential users or affected groups, so as to contrast the expected impacts or to identify new ones.

Since this phase depends so much on the nature of the project, and bearing in mind that the academic context of the FYP rarely allows to implement it completely, we let this phase as optional.

The last phase is a final reflection. Starting on the next academic year 2015-16, all students will have to include in the FYP memory a reflection on the social and environmental impacts, as well as ethical or legal issues that could be related to the project. This reflection must include the identification, description and analysis of the most significant social, environmental, ethical or legal aspects of the project carried out, both positive and negative. Therefore, synthesize the results of both the first and second phases.

When appropriate, we propose to add the explanation of how they have taken into account these aspects when undertaking the project: restrictions imposed by regulations, laws or ethical codes; risk assessment and prevention; dialogue with stakeholders; analysis of alternatives for the project design, etc. Besides, we recommend to make an assessment of the final outcome, highlighting how the risks and negative impacts have been minimized, how the positive impacts have been enhanced, as well as the overall coherence of the project with professional deontology.

Our proposal aims to take advantage of the possibilities offered by the FYP to develop the competences of social responsibility, by guiding the identification and analysis of the ethical, social and environmental aspects of the project and encouraging, when possible, its effective integration into it.

\section{CONCLUSIONS AND FUTURE PROSPECTS}

We have presented our experience in implementing the competences of social and environmental responsibility in some IT engineering degrees of the UPM. Along these years we have checked the relevance of including ethical, social and professional issues in the curriculum, as there is a general lack of knowledge of these issues, and we have observed that the students accept well both this kind of contents and these different learning methodologies.

The new degrees, updated in 2014, allow a better development of competences of social responsibility throughout the degree. In the former programs the ethical and social issues had a reduced presence, only in one subject in the first year. Now, with the new programs, these topics have improved their recognition with a specific subject. Legal and professional issues will be studied in the third year, enabling a deeper and more detailed analysis. Furthermore, a guided work related to these competences in the FYP is planned, and it can contribute to complete an effective basic training for our students.

We recognize the important role played by external demands -the Dublin Descriptors, the Spanish Council of Universities recommendations, or the proposals of accreditation agencies such as $A B E T$ and EUR-ACE- to justify to the faculty the inclusion of the competences of ethical, social and environmental responsibility into the programs. In our particular case -IT engineering degrees at the ETSISI-UPM-, we highlight the reference to the ACM Criteria and Guidelines on how to implement them. In order to reach the integration of social issues 
in engineering programs, we consider as capital the involvement of professionals associations.

Although there are aspects that need improving, we have had some positive results about the effectiveness of both our teaching and assessment methodologies. The active learning practices not only promote the acquisition of knowledge but also analytical skills, critical and holistic thinking.

The assessment of ethical and social responsibility competences is a challenge, especially when working in big groups while paying attention to all the students in a program. We are developing evaluation tools (dilemmas, cases, monographs, objective tests, etc.) and rubrics adapted to our context that allow us both to make an assessment of the students' progress and to contrast the efficacy of our methodologies.

We have identified different lines for future work. First, to improve the teaching and assessment methodologies in order to make them both more effective -improving students' learning- and more efficient, reducing the teachers workload, because it has been excessive with our current number of students. We wish to test that effectiveness measuring the students' progress in the different milestones where the competence must be developed.

Another line of work is increasing the coordination with the faculty in our School in two ways. First, increasing their participation in the subjects mentioned in section 3 , so they can provide their particular point of view on social issues from their different fields of work. Secondly, extending the implementation of competences of social responsibility into other subjects in a consistent and coordinated way. We think that it is possible because some of the current subjects in the new programs include already topics related to these competences in their syllabuses, for instance, "Artificial Intelligence" and "Software Quality". Besides, there are other thematic areas that could introduce some contents, such as topics on CSR into the subjects related to business, or regulations and cases on privacy and data protection in courses on computer security or database administration, etc.

\section{ACKNOWLEDGMENTS}

Our thanks to the Educational Innovations Projects of the UPM that had supported and funded our experience during 2012, 2013 and 2015.

\section{REFERENCES}

[1] ABET. 2015. Criteria for Accrediting Engineering Programs. Available: http://www.abet.org/accreditation/accreditationcriteria/ [2015].

[2] Association for Computing Machinery (ACM). 2013 Computer Science Curricula 2013. Curriculum Guidelines for Undergraduate Degree Programs in Computer Science. Available: http://www.acm.org/education/CS2013-finalreport.pdf [2105].

[3] Association for Computing Machinery (ACM). ACM Code of Ethics and Professional Conduct. Available: http://www.acm.org/about/code-of-ethics [2015].

[4] Association for Computing Machinery (ACM). ACM Software Engineering Code of Ethics and Professional Practice. Available: https://www.acm.org/about/se-code [2015].

[5] Boletín Oficial del Estado (BOE). 2009. Recomendaciones para la propuesta por las universidades de memorias de solicitud de títulos oficiales en los ámbitos de la Ingeniería Informática, Ingeniería Técnica Informática e Ingeniería Química. Secretaría General de Universidades. Acuerdo de 8 de junio de 2009. Available:

http://www.boe.es/diario_boe/txt.php?id=BOE-A-200912977 [2015].

[6] Bowden, P. and Smythe, V. 2008. Theories on Teaching \& Training in Ethics. Electronic Journal of Business Ethics and Organization Studies. Vol.13, No.2, pp. 19-26. http://ejbo.jyu.fi/

[7] Bragós, R., Alarcón, E., Cabrera, M., Calveras, A., Comellas, J., O'Callaghan, J., Pegueroles, J., Prat, L., Sáez, G., Sardá, J. and Sayrol, E. 2010. Proceso de inserción de competencias genéricas en los nuevos planes de estudios de la ETSETB de acuerdo con el modelo CDIO. $L X$ Congreso de Tecnologías Aplicadas a la Enseñanza de la Electrónica (Madrid, Spain, April 13-15, 2010). Available: http://taee.euitt.upm.es/actas/2010/fulldoc.pdf [2015]

[8] Brey, P.A. 2012. Anticipating ethical issues in emerging IT. Ethics and Information Technology. Vol. 14.4, pp. 305-317. DOI $=10.1007 / \mathrm{s} 10676-012-9293-\mathrm{y}$

[9] CDIO. 2011. The CDIO Syllabus 2.0. Available: http://www.cdio.org/framework-benefits/cdio-syllabus [2015].

[10] Colby, A. and Sullivan, W.M. 2008. Ethics Teaching in Undergraduate Engineering Education. Journal of Engineering Education. vol. 97 (3), pp. 327-338

[11] Conlon, E. 2010. Towards an Integrated Approach to Engineering Ethics. In Proceedings of the 3rd International Symposium for Engineering Education, (Cork, Ireland, June 30 - July 2, 2010). Available:

http://www.ucc.ie/archive/isee2010/proceedings.html [2015]

[12] Cummings, M.L. 2006. Integrating ethics in design through the value-sensitive design approach. Science and Engineering Ethics. Vol. 12, pp. 701-715. DOI= 10.1007/s11948-006-0065-0

[13] Davis, M. 2006. Integrating Ethics into Technical Courses: Micro-Insertion. Science and Engineering Ethics. Vol. 12, 717-730. DOI $=10.1007 / \mathrm{s} 11948-006-0066-\mathrm{Z}$

[14] Didier, C. \& Derouet, A. 2013. Social Responsibility in French Engineering Education: A Historical and Sociological Analysis. Science and Engineering Ethics. Vol. 19, pp. $1577-1588$

[15] ENAEE-European Network for Accreditation of Engineering Education. 2008. EUR-ACE Framework Standards. Available: http://www.enaee.eu/wpcontent/uploads/2012/01/EUR-ACE_FrameworkStandards_2008-11-0511.pdf [2015]

[16] ENAEE-European Network for Accreditation of Engineering Education. 2015. EUR-ACE Framework Standards. Available: http://www.enaee.eu/eur-ace-system/eur-aceframework-standards [2015]

[17] Engineering Education for Sustainable Development. 2004. Declaration of Barcelona. Available: https://www.upc.edu/eesd-observatory/who/declaration-ofbarcelona [2015] 
[18] Fabregat, J. 2013. Explicit training in human values and social attitudes of future engineers in Spain. Science and Engineering Ethics. Vol. 19-04., pp. 1519.

[19] Global Reporting Initiative. GRI Guidelines and Standards Settings. Available: https://www.globalreporting.org/standards [2015]

[20] Institute of Electrical and Electronics Engineers. IEEE Code of Ethics. Available: $\mathrm{http}: / / \mathrm{www}$.ieee.org/about/corporate/governance/p7-8.html [2015]

[21] International Organization for Standardization. ISO 14000. Environmental Management. Available: http://www.iso.org/iso/es/home/standards/managementstandards/iso 14000.htm [2015]

[22] International Organization for Standardization. ISO 26000. Social Responsibility. Available: $\mathrm{http}: / / \mathrm{www}$.iso.org/iso/es/home/standards/iso26000.htm [2015]

[23] Liebert, W. 2013. Preparing to Understand and Use Science in the Real World: Interdisciplinary Study Concentrations at the Technical University of Darmstadt. Science Engineering Ethics. Vol. 19, pp. 1533-1550.

[24] Lopez, D., Sanchez, F., Vidal, E. and Pegueroles, J.M.A. 2014. A methodology to introduce sustainability into the final year project to foster sustainable engineering projects. In Proceedings of Frontiers in Education Conference (FIE). Ed. IEEE, (Madrid, Spain, 22-25 Oct. 2014), pp. 1-7.

[25] Minano, R. and Fernandez Aller, C. 2015, Guia para trabajar la competencia de responsabilidad socialy ambiental. Available: http://oa.upm.es/35542/ [2015]

[26] Rathje, D., Spitzer, H. and Zandvoort, H. 2008. How to prepare students for a responsible use of science and engineering. Results from the Workshop Teaching Ethics and Peace to Science and Engineering Students. Ed. H. Spitzer. (Hamburg, Deutchland,15-17 Oct 2008). Available: http://www.dirk-rathje.de/brochure-teaching-responsibleuse-2008.pdf [2015]

[27] Segalas, J. 2009. Engineering Education for a Sustainable Future. Doctoral Thesis. Barcelona Tech, UPC.
[28] Shuman, L.J., Sindelar,M.F., Besterfield-Sacre, M., Pinkus, H.W., Pinkus, R.L., Miller, R.L., Olds, B.M. and Mitcham, C. 2004. Can Our Students Recognize and Resolve Ethical Dilemmas? Proceedings of the 2004 American Society for Engineering Education Annual Conference \& Exposition . Ed. American Society for Engineering Education.

[29] UNESCO. Teaching and learning for a sustainable future. http://www.unesco.org/education/tlsf/ [2015]

[30] United Nations Environment Programme UNEP. 2009, Guidelines for Social Life Cycle Assessment of Products. Available: http://www.cdo.ugent.be/publicaties/280.guidelinessLCA.pdf. [2015]

[31] Universidad Politécnica de Madrid. Cátedra Unesco. 2010. Modelo Educativo UPM. Available: http://catedraunesco.es/me/UPM/Inicio.html [2015]

[32] Universidad Politécnica de Madrid. Innovación Educativa. Competencias genéricas. Recursos de apoyo al profesorado. http://innovacioneducativa.upm.es/competenciasgenericas/competencias [2015]

[33] World Business Council for Sustainable Development (WBCSD). Business Solutions for a Sustainable World. Social Impacts. http://www.wbesd.org/social-impact.aspx [2015]

[34] Wright, D. 2011. A framework for the ethical impact assessment of information technology. Ethics and Information Technology, vol. 13.3, pp. 199-226. DOI= 10.1007/s10676-010-9242-6.

[35] Zandvoort, H., Børsen, T., Deneke, M. and Bird, S.J. 2013. Editors' Overview Perspectives on Teaching Social Responsibility to Students in Science and Engineering. Science and Engineering Ethics, vol. 19, pp. 1413-1438. DOI $=10.1007 / \mathrm{s} 11948-013-9495-7$ 